\title{
Effects of Steps to Success Exercise Program in Weight Management For Psychiatric Patients Taking Atypical Antipsychotic Drugs
}

\author{
Homelo V. Estoque* \\ Far Eastern University, Philippines \\ Corresponding author: hestoque@feu.edu.ph
}

\begin{abstract}
Background: Patients taking atypical antipsychotics are in danger of antipsychotic-induced weight gain. Weight increases rapidly in the initial period after starting antipsychotics. Cardiovascular and cerebrovascular morbidity and mortality and reduced quality of. Both nonpharmacologic prevention and intervention strategies have shown modest effects on weight. Changes in physical appearance can lead to body image issues and problems with self-esteem, which in turn could lead to poor compliance with medication.

Purpose: This study aimed to evaluate the effectiveness of an exercise program that can benefit patients who are gaining weight related to atypical antipsychotic agent intake.

Methods: A quasi-experimental research design was undertaken. The research setting was held in a general tertiary medical teaching/training medical facility owned by the Philippine government. There are 31 respondents for this study 12 were males and 19 were females who were chosen from the list of the in-patients utilizing the universal sampling technique. Data were gathered using a self-formulated tool to collect mostly demographic data which is adopted from the National Alliance for Mental Health.

Results: Patients' diagnosis tends to have a positive relationship with weight loss. Respondents diagnosed with bipolar with psychotic features showed to have loss weight more than the diagnosed with schizophrenia. The results of this study showed that patient's adhering to the exercise program had lost weight after the course.

Conclusion: Activity and exercise are especially important for people living with mental illness. Furthermore, physical activity does not only help patients manage their weight but to serve as diversional activity that adds vitality for patients in the facility.
\end{abstract}

Keywords: Atypical Antipsychotic Drugs, Induced Weight Gain, Exercise Program, Schizophrenia, Bipolar. 


\section{Journal Of Nursing Practice}

http://thejnp.org

ISSN: 2614-3488 (print); 2614-3496 (online)

Vol.4 No.1. October 2020. Page.84-96

\section{BACKGROUND}

The introduction of a new group of antipsychotic drugs, called atypical because of the properties differing them from classical neuroleptics, gave hope for the beginning of a new era in treatment of psychoses, including schizophrenia. Patients with psychiatric disorders such as bipolar disorder, depression and schizophrenia often take medication for prolonged periods. However, many of the psychotropic drugs in use today cause significant weight gain (Malhi et al., 2001).

Second-generation antipsychotics (SGAs), in comparison with first-generation antipsychotics, are associated with a greater risk for antipsychotic-induced weight gain although this oversimplification should be clarified by distinguishing across different antipsychotic drugs. Among SGAs, olanzapine appears to cause the most significant weight gain, while ziprasidone seems to cause the least. (Martínez-Ortega et al., 2013)

Nursing profession has played a vital role in the health promotion, disease prevention and wellness. Thus, the researcher conducted this study to the induced weight gain effects of atypical antipsychotics medications. Weight gain as defined is bodybuilding that increases muscle mass and body weight. Moreover, it is established that weight gain is a frequent side effect of antipsychotic medication which has serious implications for patient's health and wellbeing. Weight gain is important both from the clinical subjective point of view as associated with serious somatic consequences and as a source of enormous mental distress (Faulkner et al., 2007).

Atypical antipsychotics (AT) and stress are related to weight gain in individuals with severe mental illness (Hampton et al., 2018). People with serious mental illnesses (SMI) such as schizophrenia, bipolar disorder and major depressive disorder, have poorer physical health and significantly reduced life expectancy compared with the general population (Every-Palmer et al., 2018).

Further, Patients who are taking atypical antipsychotics are in danger of antipsychotic-induced weight gain. Weight increases rapidly in the initial period after starting antipsychotics (Dayabandara et al., 2017a). Further, cardiovascular and cerebrovascular morbidity and mortality and reduced quality of. Both nonpharmacologic prevention and intervention strategies have shown modest effects on weight. Furthermore, changes in physical appearance can lead to body image issues and problems with selfesteem, which in turn could lead to poor compliance with medication (Eapen \& John, 2011).

Currently there are no established intervention program for patients whatever their diagnosis, who are taking atypical antipsychotic medication against induced weight gain in the research facility and thus the purpose of this study was to establish an exercise program that can benefit patients not only in the research locale but also to other patient who are experiencing the atypical antipsychotic induced weight gain.

\section{OBJECTIVE}

This study aimed to evaluate the effectiveness of an exercise program that can benefit patients who are gaining weight related to atypical antipsychotic agent intake.

\section{METHODS}

Study Design

This study was designed to use quasi-experimental design; however, it lacks randomization because it used the universal sampling method that served as the baseline data after respondent underwent the intervention program. This scheme permits the researcher to examine the change in respondents' weight. 


\section{Journal Of Nursing Practice}

http://thejnp.org

ISSN: 2614-3488 (print); 2614-3496 (online)

Vol.4 No.1. October 2020. Page.84-96

This study utilized an exercise program entitled "Steps for Success" adapted from the National Alliance for Mental Health. Respondents where purposively selected from the group of patients admitted in the psychiatric facility. Thirty in-patients were selected according to a set of criteria where the researcher deemed to be significant for the purpose of the study. Participants of the program underwent a 30-minute exercise program, comprising of a 10-minute routine activity, 10-minute exercises and 10-minute cool down activities. This exercise program was instituted for a total of four weeks or 28 days. According to the study entitled Second Generation Antipsychotic Use in Schizophrenia and Associated Weight Gain: A Critical Review and Meta-Analysis of Behavioral and Pharmacologic Treatments, a small group of 16 participants of which eight had schizophrenia, have found out that weight loss can start as early as four weeks (Das et al., 2012).

The degree of participation of the participants varies as to their attention span. Here, patients with mental health disorder such as those diagnosed with bipolar disorder has impaired attention span (Camelo et al., 2013). This may delimit the goals of the program, but it is manageable.

In addition, at the end of four weeks intervention, effectiveness was evaluated according to the set of parameters to judge the program to be effective. Moreover, it is also considered that participation of the respondents is also perceived to constrain in effect to their diagnoses, thus necessity to include it as one of the variables of the study.

Furthermore, this study does not aim to cure any health conditions that the respondents have during the course of the study but to determine the effectiveness of health promotion towards healthy body weight maintenance among patients taking antipsychotic agents.

\section{Ethical Procedures}

Ethical issues were considered in undertaking this study in which all article used were properly cited. Ethical review board of the author's university affiliation approved the study. Further, approval from the concerned individuals was secured before data collection. The gathered data were handled with utmost respect and confidentiality. As such, the researcher intensifies consent letters to the institution where the study was conducted. The participants were made to understand the purposes of the research, the expected duration, their right to decline to participate and to withdraw from the research; the foreseeable consequences of declining or withdrawing and the potential risk. Limitations of confidentiality were also explained, the incentive for participation, and whom to contact with regard to questions about the research and their rights. Confidentiality was strictly observed in the whole process of research. More so, voluntary participation was ensured.

\section{Participants and Sampling Scheme}

A total of thirty-one (31) respondents were chosen to participant in this study of which twelve are male and nineteen were females. This study utilized the universal sampling technique since [explain why universal sampling was used]. The patient's present weight was measured, and their individual medication regimen was reviewed. After measurement and review, respondents and participants for this study were selected based on the criteria. The criteria for selection was a) taking atypical antipsychotic medication b) with weight gain more than 10 percent of the baseline weight and c) must be an in-patient of the psychiatric facility. The exclusions include, out-patient, those weight gain which is not more than ten $(10 \%)$ percent of the baseline weight and those who are physically unable to do the activities of daily living. 


\section{Journal Of Nursing Practice}

http://thejnp.org

ISSN: 2614-3488 (print); 2614-3496 (online)

Vol.4 No.1. October 2020. Page.84-96

Research Instrument

The basic tool that the researcher used in order to obtain information from the respondents was the researcher made questionnaire adapted from the exercise program entitled "Steps to Success" from the National Alliance for Mental Health. A questionnaire deals with the respondent's demographic profile in terms of gender, age, medication taken, anthropometric This was the exercise program that was implemented to the respondents. This program is designed by the Center for Disease Control and Prevention to be administered to mentally challenged individuals. This tool includes recommended types of exercise that can suit best the above-mentioned patients.

A questionnaire deals with the patient's demographic profile in terms of gender, age, medication taken, anthropometric measurements and the patient's diagnosis was made available as well. It contains the history of the patient; this includes how long the patient had been in atypical antipsychotic therapy, weight history as well as the nutritional assessment of the patient.

To measure the weight differences, weight before the treatment was obtained first as to contrast it to the weight post treatment and this was recorded in the questionnaire.

A weighing scale in the facility was used in obtaining the daily weight of the patients. Patient's weights are measured before and after the program using the same weighing scale, using the same clothing and the same time daily.

Moreover, the research instrument contains all necessary and relevant information that involves weight management of these patients. The self-made questionnaire first part is the demographic data, which describes the patient's profile, the preliminaries which includes the baseline weight, the activities of daily living and the kind of diet the patient is taking. Part two of the questionnaire describes the degree of patient's participation in the intervention program, recent changes in the diet and the comments for the intervention program. The Step Up to Success Program is already described in the above statements and lastly, the weight monitoring chart serves as a tool to tract the changes in the patient's weight throughout the intervention program.

\section{Statistical Treatment of Data}

The following tools were used for the analysis of the data gathered:

To determine the profile of the respondents in terms of age and gender, the descriptive statistics was used using the mean, median, mode and standard deviation. For the brand of atypical antipsychotic and patient's diagnosis, the frequency and percentage were used.

To find out the significant reduction of weights among patients after the intervention, the paired t-test was used before and after the intervention.

To know if significant relationship between age, gender, and brand of atypical antipsychotic agent used, patient's diagnosis and weight loss exist, the multiple linear regression was used. All data was set at 0.06 level of significance for the rejection and acceptance of null hypothesis using the Minitab software version 15

\section{RESULTS}

This study mostly composed of female respondents compared to males. This is due to the fact that at the time of the study there was more female admitted patients compared to males. Bipolar disorder is more common in women that in men, 1 in 4 women will require treatment for depression at some time, compared to 1 in $10 \mathrm{men}$. The reasons for this are unclear but are thought to be due to both social and biological factors. It has also been suggested that depression in men may have been may have been under diagnosed because 
Journal Of Nursing Practice

http://thejnp.org

ISSN: 2614-3488 (print); 2614-3496 (online)

Vol.4 No.1. October 2020. Page.84-96

they present to their General practitioner with different symptoms (National Institute for Clinical Excellence, 2003).

Moreover, researchers found out that when it comes to mental illness sexes differ. Women are more likely to be diagnosed with anxiety and depression, while men tend toward substance abuse or antisocial disorders (Vaillant, 2003).

Furthermore, it is also supported the idea above that women are more likely to have been treated for a mental health problem than men (29\% compared to 17\%) (Gunnell \& Harbord, 2003). This could be because, when asked, women are more likely to report symptoms of common mental health problems.

Moreover, the result revealed that there are more patients prescribed with risperidone compared to other antipsychotic brands. This increase in risperidone use is due to the fact that only one doctor manages most of the respondents, hence it showed that this is the drug preferred by the doctor. Moreover, risperidone as a second-generation antipsychotic drug is less sedating compared to other atypical antipsychotics thus allow the patient to continue with usual activities without fear of encountering accidents related to sedation. Furthermore, Risperidone is one of a number of 'atypical antipsychotics' which are currently being marketed for the treatment of those with schizophrenia, largely on the basis of claims of improved tolerability and effectiveness compared to much cheaper conventional antipsychotics (Gilbody et al., 2016). However, in this same study, the authors also noted that risperidone possess less favorable effects such as it is less acceptable to clients because of its higher occurrence of extrapyramidal side effects, and slight improvement of mental states. Thus, despite the notable unfavorable effects, it is not surprising that this medication will be favored more in the treatment of mental illness.

Risperidone's relative lack of extrapyramidal syndromes at effective doses indicates that risperidone has a substantially better efficacy/side-effect ratio when compared with conventional compounds. Patients who are unable to tolerate other antipsychotic at does that are needed to control psychotic symptoms are likely to respond better to risperidone. It may also be more effective agent for patients with negative symptoms and in certain groups unresponsive to trials of typical agents. Thus, with these benefits that patient can get from risperidone, no doubt that psychiatrist prescribes such medication.

The study showed that most of the respondents are diagnosed with bipolar disorder with psychotic features followed by clients with schizophrenia. Patients with bipolar disorders are usually admitted in the hospitals because when these patients experience relapse other conditions, they become dangerous to both themselves and to those individuals around them. Furthermore, patients at the height of their manic episode will be difficult to handle by their caregivers, thus, most caregivers would opt for their patients to be admitted in the hospital than being cared at home.

The issue of violence is particularly perplexing in connection with the role of psychiatric disorders as contributing factors. Several psychiatric conditions, including bipolar disorder, have been implicated with increased rates of violent behavior (Feldmann, 2001). Bipolar patients are prone to agitation that may result in impulsive aggression during manic and mixed episodes. However, the breast spades, which can involve intense dysphoria with agitation and irritability, may also carry a risk of violent behavior. Even during euthymia, bipolar patients -especially those with comorbid features of borderline personality disorder -may have chronic impulsivity that predisposes them to aggression and thus would post a need to be admitted to be managed and for safety to be instituted not just for the patient itself but for people around them as well.

Moreover, a study entitled "predictors of Trait aggression in bipolar disorder" it was mentioned that aside from treating the manic episode, other measures may be used if needed 


\section{Journal Of Nursing Practice}

http://thejnp.org

ISSN: 2614-3488 (print); 2614-3496 (online)

Vol.4 No.1. October 2020. Page.84-96

to quickly control aggressive behavior. These include sedating medication, seclusion, and restraint. it is important to provide an environment that minimizes overstimulation and includes clear interpersonal communication and limit setting (Garno et al., 2008). This can all be done in managed when a patient is confined in a mental health facility. Thus, more families opted to have their loved ones admitted.

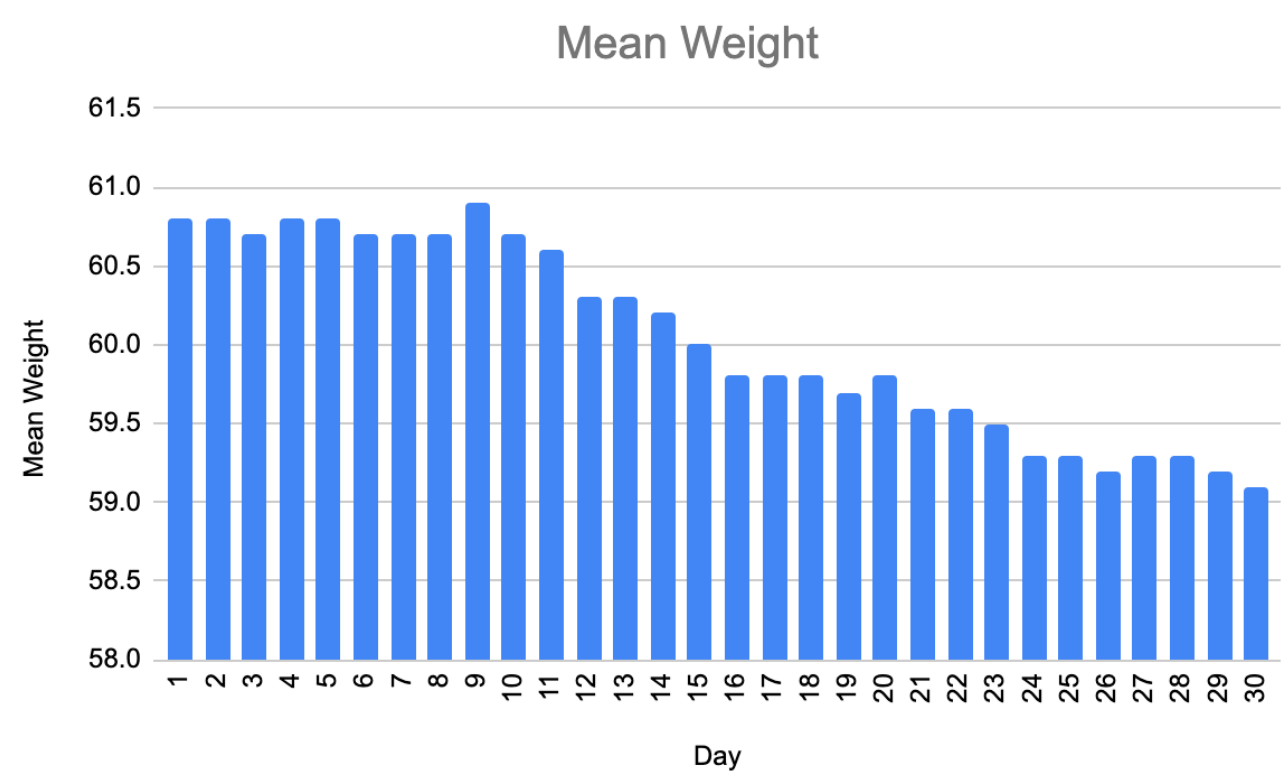

Figure 1. Mean weight of the respondents in 30 days of Exercise

Figure 1 shows the mean weights of the respondents during the 30- day intervention period can be gleaned from the figure that maximum weight gain of the respondents was attained during the 9th day of the implementation period. This can be viewed as a challenge to the study which can be attributed to low expectations of weight loss attempts, reduced support from family and friends, adoption of unhealthy lifestyles, use of food as a coping strategy and attrition from weight loss programs (National Obesity Observatory, 2011). This increase is also due to the fact that clients' daily routine is, once the food is served, they will have to get in line for medication then they can go sleeping the rest of the day. The first day of the program the participants are still adjusting to their activities being introduced. However, the challenge to the study did not persist for along upon the establishment of the regular implementation of the exercise program. Day by day the respondents anticipate that they will be having the exercise program and weighing activities. In the second week of exercise program, they were nursing students who were assigned to the facility and they too conducted their own programs which include exercise programs but not in a regular basis. The researcher noticed that those respondents who were regularly participating in the program showed their mean weights gradually reduced with the highest weight loss attained on the 26th day of the implementation.

In the study conducted by the team from John Hopkins University hospital, the author quoted that "we sought to dispel the perception that lifestyle programs don't work in this population". we brought a weight-loss program to them, tailored to the needs some people with serious mental illness (Wood, 2013). Moreover, the author concluded that their study was indeed helpful and effective in managing the weight of those mentally ill patients. 


\section{Journal Of Nursing Practice}

http://thejnp.org

ISSN: 2614-3488 (print); 2614-3496 (online)

Vol.4 No.1. October 2020. Page.84-96

\begin{tabular}{|l|c|c|c|c|c|}
\hline & $\mathrm{N}$ & Mean & StDev & SE Mean & P Value \\
\hline Baseline & 31 & 60.87 & 6.30 & 1.13 & \\
\hline Weight After & 31 & 59.23 & 6.49 & 1.17 & 0.00 \\
\hline Difference & 31 & 1.645 & 1.199 & 0.215 & \\
\hline
\end{tabular}

95\% CI for mean difference: (1.206, 2.085)

$\mathrm{T}-\mathrm{Test}$ of Mean difference $=0($ vs not 0$): \mathrm{T}-\mathrm{Value}=7.64$

Table 1. Paired T-Test and CI: Baseline, Weight After

Figure 2 showed that there is a significant reduction of the respondent's weight after the intervention program had been implemented. In a study entitled Management of Antipsychotic-induced weight gain: Prospective Naturalistic Study of the Effectiveness of a Supervised Exercise Program, it has been conclusively ended that body weight and metabolic risk profile in patients receiving a typical antipsychotic medications can be effectively managed with a weight control program including physical activity (Poulin et al., 2007). Thus, in institutionalized mentally ill manage with second-generation antipsychotics a regular exercise program is needed to manage drug-induced weight gain.

In a study, it was found out that lifestyle interventions appear effective for treating overweight and obesity among people with serious mental illness. These included behavioral interventions and interventions targeting self-monitoring, dietary changes, nutrition education, fitness, exercise or physical activity (Naslund et al., 2017).

Moreover, it was concluded that the weight gain liabilities of antipsychotic drugs are partly associated with their ability to increase appetite. The long-term treatment with atypical antipsychotics is the same time increasing their appetite and weight (Werneke et al., 2013).

Nonpharmacologic interventions are important in the management of AIWG. Dietary counseling, exercise interventions, cognitive and behavioral strategies appear to be equally effective as individual and group therapies. All patients who are commenced on antipsychotics should be routinely provided with nutritional counseling and advice about a healthy lifestyle. Those who gain weight should be enrolled in structured program which monitors the adherence of patients to the management plan. Nonpharmacologic interventions appear to be more effective in patients treated with antipsychotics with a high propensity for weight gain (Dayabandara et al., 2017b).

\begin{tabular}{|c|c|c|}
\hline Gender & f & $\%$ \\
\hline Male & 12 & 38.71 \\
\hline Female & 19 & 61.29 \\
\hline Total & 31 & 100 \\
\hline
\end{tabular}

Table 2. Profile of the Respondents in Terms of Gender

\begin{tabular}{|c|c|}
\hline Variables & P Value \\
\hline Weight & 0.315 \\
Gender & \\
\hline
\end{tabular}

Table 3. Weight Loss versus Gender

Moreover, the computed probability value of 0.315 is greater than 0.05 . This means that gender has nothing to do with weight loss. In one study, the analysis indicated that although men and women reported different motivation for and approaches to weight loss 


\section{Journal Of Nursing Practice}

http://thejnp.org

ISSN: 2614-3488 (print); 2614-3496 (online)

Vol.4 No.1. October 2020. Page.84-96

prior to their enrollment in the study, weight-related behaviors at study entry were similar, including meal patterns and leisure time physical activity. Further, in another study entitled "Acute weight gain, gender, and therapeutic response to antipsychotics in the treatment of patients with schizophrenia" the results concluded and indicated that gender was not a significant variable.

\begin{tabular}{|c|c|c|}
\hline Brand of Antipsychotic & f & $\%$ \\
\hline Resperidone & 22 & 70.97 \\
\hline Olanzapine & 5 & 16.13 \\
\hline Quetiapine & 2 & 06.45 \\
\hline Aripiprazole & 2 & 06.45 \\
\hline Total & 31 & 100 \\
\hline
\end{tabular}

Table 4. Profile of the Respondents in Terms of Brand of Antipsychotic Medication used

\begin{tabular}{|c|c|}
\hline Variables & P Value \\
\hline Weight & 0.301 \\
Brand & \\
\hline
\end{tabular}

Table 5. Weight Loss versus Brand

In considering the brand of atypical antipsychotic, in a study entitled "Serious Mental Illness No Barrier To Weight Loss Success" it was concluded that, no matter if the patient is taking medications which are known to cause weight gain such as a typical antipsychotic medications and mood stabilizers for clients who are bipolar it showed that where the institution of this exercise program the respondents lose weight (Daumit et al., 2013).

In addition, another study concluded that patients were able to lose weight no matter what a typical antipsychotic they were receiving (olanzapine, Clozapine, risperidone or quetiapine) with no significant differences between the drugs. The study was designed to detect differences between drugs (Vreeland et al., 2003).

\begin{tabular}{|c|c|c|}
\hline Patient's Diagnosis & $\mathrm{f}$ & $\%$ \\
\hline Schizophrenia with Auditory Hallucination & 2 & 06.45 \\
\hline Disorganized Schizophrenia & 8 & 25.81 \\
\hline Schizophrenia & 9 & 29.03 \\
\hline Bipolar with Psychotic Features & 12 & 38.71 \\
\hline Total & 31 & 100 \\
\hline
\end{tabular}

Table 6. Profile of the Respondents in Terms of Patient's Diagnosis

\begin{tabular}{|c|c|}
\hline Variables & P Value \\
\hline Weight & 0.023 \\
Gender & \\
\hline
\end{tabular}

Table 7. Weight Loss versus Diagnosis

Further, the study found out through a computed probability value of 0.023 that is lesser than 0.05 that the diagnosis of the client has something to do with weight loss.

In a study entitled "Exercise and Mood-Exploring the Role Of Exercise And Regulating Stress Reactivity In Bipolar Patients" it has been found out that depressive episodes and 


\section{Journal Of Nursing Practice}

http://thejnp.org

ISSN: 2614-3488 (print); 2614-3496 (online)

Vol.4 No.1. October 2020. Page.84-96

bipolar depressions are associated with a higher degree of agitation, hypersomnia, and more cycle model reputation thus leading to weight loss. Further, patients diagnosed with bipolar tends to lose weight more compared to schizophrenia patients (Edenfield, 2008). This is supported by the fact that Bipolar patients' characteristics such as being restless, sleeping little, behaving impossibly and taking part in a lot of pleasurable, high risk behaviors, such as spending sprees, impulsive sex, and impulsive business investments.

A review of empirically validated weight interventions for individuals with schizophrenia found that these programs emphasized nutrition, exercise, and behavioral change to stabilize or reduce weight. Subsequent reviews and results of meta-analyses support the efficacy of behavioral or psychoeducation-based interventions to stabilize weight and promote modest weight loss among individuals with schizophrenia. Components of these psychosocial interventions have included: 1) psychoeducation regarding diet and exercise, 2) goal setting, 3) self-monitoring of food and physical activity level, 4) caloric restriction, and 5) increase in physical activity. Clinical trials have found support for modest weight loss among individuals with severe mental illness who received the psychosocial intervention relative to those in the control condition (Niv et al., 2014). Participating in your chosen activities for at least 20 minutes per day, around four times per week, working up to 45 minutes per session can do a lot more, said the organization.

Additionally, participants with mental illnesses such as schizophrenia, bipolar disorder or major depression no barrier to weight loss. In a behavioral program such as exercise, it has been found that participants lost more weight as the intervention went on. These findings say that it took a while to see some changes but once this modification is adapted by the respondents, positive results is achievable (Daumit et al., 2013).

Furthermore, symptoms of depression and bipolar disorder are similar to those of other forms of depression. Individuals experience empty, sad, or irritable mood throughout most of the day and although in bipolar depression increased appetite and weight gain are commonly experienced weight loss especially if they undergo into behavioral therapies such as exercise.

\section{DISCUSSION}

The results analysis indicates that an active lifestyle is important for everyone. This is particularly true for those living with schizophrenia and other serious mental illnesses (e.g. bipolar disorder) who are treated with second-generation, a typical antipsychotic medication (SGA's) because they are more vulnerable to obesity. Activity and exercise are especially important for people living with mental illness. It is a fact the patients gain weight in the course of treatment with atypical antipsychotic and thus this needs to be addressed. Furthermore, physical activity does not only help patients manage their weight but to serve as diversional activity that adds vitality for patients in the facility.

Moreover, the facility doesn't have a structured exercise program and that it is only when there are student nurses who are on duty to the facility that these patients get to have exercise programs. The researcher recommended the creation of a therapeutic group that is focused and regular implementation of an exercise program this led by an assigned patient leader -facilitator, we're in each patient who are ready to go and mentally stable are alternately assigned to lead a therapeutic group.

Hence, the researcher recommends the facility may adopt the "steps to success program "adapted from the National Alliance for Mental Illness. This will help the patients utilize their idle time while confined in the facility 


\section{Journal Of Nursing Practice}

http://thejnp.org

ISSN: 2614-3488 (print); 2614-3496 (online)

Vol.4 No.1. October 2020. Page.84-96

\section{CONCLUSION}

Activity and exercise are especially important for people living with mental illness. Furthermore, physical activity does not only help patients manage their weight but to serve as diversional activity that adds vitality for patients in the facility.

\section{CONFLICTS OF INTEREST}

The author declares there are no significant competing financial, professional, or personal interests that might have influenced the performance or presentation of the work described in this manuscript 


\section{Journal Of Nursing Practice}

http://thejnp.org

ISSN: 2614-3488 (print); 2614-3496 (online)

Vol.4 No.1. October 2020. Page.84-96

\section{REFERENCES}

About Mental Illness - National Alliance on Mental Illness - Iowa, Inc. - National Alliance on Mental Illness - Iowa, Inc. (n.d.). Retrieved June 23, 2020, Retrieved from https://namiiowa.org/about-mental-illness/

Camelo, E. V. M., Velasques, B., Ribeiro, P., Netto, T., \& Cheniaux, E. (2013). Attention impairment in bipolar disorder: A systematic review. Psychology and Neuroscience, 6(3), 299-309. https://doi.org/10.3922/j.psns.2013.3.08

Chaput, J., Saindon, J., Gauthier, Y., Lancto, G., Vincent, A., Gagnon, S., \& Tremblay, A. (2008). May, 1-11. https://doi.org/10.1080\%2F00048670701689428

Das, C., Mendez, G., Jagasia, S., \& Labbate, L. (2012). Second-generation antipsychotic use in schizophrenia and associated weight gain: A critical review and meta-analysis of behavioral and pharmacologic treatments. Annals of Clinical Psychiatry: Official Journal of the American Academy of Clinical Psychiatrists, 24, 225-239. Retrieved from

https://www.ingentaconnect.com/contentone/fmc/acp/2012/00000024/00000003/art 00006

Daumit, G. L., Dickerson, F. B., Wang, N. Y., Dalcin, A., Jerome, G. J., Anderson, C. A. M., Young, D. R., Frick, K. D., Yu, A., Gennusa, J. V., Oefinger, M., Crum, R. M., Charleston, J., Casagrande, S. S., Guallar, E., Goldberg, R. W., Campbell, L. M., \& Appel, L. J. (2013). A behavioral weight-loss intervention in persons with serious mental illness. New England Journal of Medicine, 368(17), 1594-1602. https://doi.org/10.1056/NEJMoa1214530

Dayabandara, M., Hanwella, R., Ratnatunga, S., Seneviratne, S., Suraweera, C., \& de Silva, V. A. (2017a). Antipsychotic-associated weight gain: Management strategies and impact on treatment adherence. Neuropsychiatric Disease and Treatment, 13, 22312241. https://doi.org/10.2147/NDT.S113099

Dayabandara, M., Hanwella, R., Ratnatunga, S., Seneviratne, S., Suraweera, C., \& de Silva, V. A. (2017b). Antipsychotic-associated weight gain: Management strategies and impact on treatment adherence. In Neuropsychiatric Disease and Treatment (Vol. 13, pp. 2231-2241). Dove Medical Press Ltd. https://doi.org/10.2147/NDT.S113099

Eapen, V., \& John, G. (2011). Weight gain and metabolic syndrome among young patients on antipsychotic medication: What do we know and where do we go? Australasian Psychiatry, 19(3), 232-235. https://doi.org/10.3109/10398562.2010.539609

Edenfield, T. M. (2008). Exercise and mood: Exploring the role of exercise in regulating stress reactivity in bipolar disorder. Dissertation Abstracts International: Section B: The Sciences and Engineering, 68(8-B), 5566. Retrieved from http://search.ebscohost.com/login.aspx?direct=true \&db=psyh\&AN=2008-99040257\&lang $=$ es\&site $=$ ehost-live\&scope $=$ site

Every-Palmer, S., Huthwaite, M. A., Elmslie, J. L., Grant, E., \& Romans, S. E. (2018). Longterm psychiatric inpatients' perspectives on weight gain, body satisfaction, diet and physical activity: A mixed methods study 11 Medical and Health Sciences 1117 Public Health and Health Services. BMC Psychiatry, 18(1), 1-10. https://doi.org/10.1186/s12888-018-1878-5

Faulkner, G., Cohn, T., \& Remington, G. (2007). Interventions to reduce weight gain in schizophrenia. Cochrane Database of Systematic Reviews, 1, 1-163. https://doi.org/10.1002/14651858.CD005148.pub2

Feldmann, T. B. (2001). Bipolar disorder and violence. Psychiatric Quarterly, 72(2), 119129. https://doi.org/10.1023/A:1010315509112 


\section{Journal Of Nursing Practice}

http://thejnp.org

ISSN: 2614-3488 (print); 2614-3496 (online)

Vol.4 No.1. October 2020. Page.84-96

Foy, C. G., Rejeski, W. J., Berry, M. J., Zaccaro, D., \& Woodard, C. M. (2001). Gender moderates the effects of exercise therapy on health-related quality of life among COPD patients. Chest, 119(1), 70-76. https://doi.org/10.1378/chest.119.1.70

Garno, J. L., Gunawardane, N., \& Goldberg, J. F. (2008). Predictors of trait aggression in bipolar disorder. Bipolar Disorders, 10(2), 285-292. https://doi.org/10.1111/j.13995618.2007.00489.x

Gilbody, S., Bagnall, A. M., Duggan, L., \& Tuunainen, A. (2016). Risperidone versus other atypical antipsychotic medication for schizophrenia. Cochrane Database of $\begin{array}{lll}\text { Systematic Reviews, 2016(9), 2-5. } & \text { 2019 }\end{array}$ https://doi.org/10.1002/14651858.CD002306.pub2

Gunnell, D., \& Harbord, R. M. (2003). Better or worse: a longitudinal study of the mental health of adults living in private households in Great Britain. Semantic Scholar. Retrieved from http://hdl.handle.net/10068/394479

Hampton, J. N., Trotman, H. D., Addington, J., Bearden, C. E., Cadenhead, K. S., Cannon, T. D., Cornblatt, B. A., Mathalon, D. H., McGlashan, T. H., Tsuang, M. T., Perkins, D. O., Seidman, L. J., Woods, S. W., \& Walker, E. F. (2018). The relation of atypical antipsychotic use and stress with weight in individuals at clinical high risk for psychosis. Stress and Health, 34(5), 591-600. https://doi.org/10.1002/smi.2819

Malhi, G. S., Mitchell, P. B., \& Caterson, I. (2001). Why getting fat, Doc? Weight gain and psychotropic medications. Australian and New Zealand Journal of Psychiatry, 35(3), 315-321. https://doi.org/10.1046/j.1440-1614.2001.00891.x

Manderscheid, R. W., Ryff, C. D., Freeman, E. J., McKnight-Eily, L. R., Dhingra, S., \& Strine, T. W. (2010). Evolving definitions of mental illness and wellness. Preventing Chronic Disease, 7(1). Retrieved from https://www.ncbi.nlm.nih.gov/pmc/articles/PMC2811514/

Martínez-Ortega, J. M., Funes-Godoy, S., Díaz-Atienza, F., Gutiérrez-Rojas, L., PérezCostillas, L., \& Gurpegui, M. (2013). Weight gain and increase of body mass index among children and adolescents treated with antipsychotics: A critical review. European Child and Adolescent Psychiatry, 22(8), 457-479. https://doi.org/10.1007/s00787-013-0399-5

Miller, W. C., Koceja, D. M., \& Hamilton, E. J. (1997). A meta-analysis of the past 25 years of weight loss research using diet, exercise or diet plus exercise intervention. International Journal of Obesity, 21(10), 941-947. https://doi.org/10.1038/sj.ijo.0800499

Naslund, J. A., Whiteman, K. L., McHugo, G. J., Aschbrenner, K. A., Marsch, L. A., \& Bartels, S. J. (2017). Lifestyle interventions for weight loss among overweight and obese adults with serious mental illness: A systematic review and meta-analysis. In General Hospital Psychiatry (Vol. 47, pp. 83-102). Elsevier Inc. https://doi.org/10.1016/j.genhosppsych.2017.04.003

Niv, N., Cohen, A. N., Hamilton, A., Reist, C., \& Young, A. S. (2014). Effectiveness of a psychosocial weight management program for individuals with schizophrenia. Journal of Behavioral Health Services and Research, 41(3), 370-380. https://doi.org/10.1007/s11414-012-9273-3

Poulin, M. J., Chaput, J. P., Simard, V., Vincent, P., Bernier, J., Gauthier, Y., Lanctôt, G., Saindon, J., Vincent, A., Gagnon, S., \& Tremblay, A. (2007). Management of antipsychotic-incluced weight gain: Prospective naturalistic study of the effectiveness of a supervised exercise programme. Australian and New Zealand $\begin{array}{llll}\text { Journal of Psychiatry, } & \text { 41(12), }\end{array}$ https://doi.org/10.1080/00048670701689428 


\section{Journal Of Nursing Practice}

http://thejnp.org

ISSN: 2614-3488 (print); 2614-3496 (online)

Vol.4 No.1. October 2020. Page.84-96

Vaillant, G. E. (2003). Mental Health. American Journal of Psychiatry, 160(8), 1373-1384. https://doi.org/10.1176/appi.ajp.160.8.1373

Vreeland, B., Minsky, S., Menza, M., Radler, D. R., Roemheld-Hamm, B., \& Stern, R. (2003). A program for managing weight gain associated with atypical antipsychotics. Psychiatric Services, 54(8), 1155-1157. https://doi.org/10.1176/appi.ps.54.8.1155

Werneke, U., Taylor, D., \& Sanders, T. A. B. (2013). Behavioral interventions for antipsychotic induced appetite changes. Current Psychiatry Reports, 15(3). https://doi.org/10.1007/s11920-012-0347-y

Woo, J. S., Derleth, C., Stratton, J. R., \& Levy, W. C. (2006). The influence of age, gender, and training on exercise efficiency. Journal of the American College of Cardiology, 47(5), 1049-1057. https://doi.org/10.1016/j.jacc.2005.09.066

Wood, B. J. (2013). People With Serious Mental Illness Can Lose Weight, Too. 1-3. 